\title{
Automated Closed Loop Control of Inspired Oxygen Concentration
}

\author{
Nelson Claure MSc PhD and Eduardo Bancalari MD
}

\author{
Introduction \\ Systems of Closed Loop $\mathrm{F}_{\mathrm{IO}_{2}}$ Control \\ Oxygenation Monitoring \\ Control Algorithms and Oxygen Delivery Devices \\ Effects of Closed Loop $\mathrm{F}_{\mathrm{IO}_{2}}$ on Oxygenation, Oxygen Exposure, and \\ Resource Utilization \\ In the Neonate \\ In the Adult \\ Important Considerations and Possible Disadvantages \\ Summary
}

\begin{abstract}
Oxygen therapy is extensively used in premature infants and adults with respiratory insufficiency. In the premature infant the goal during manual control of the $\mathrm{F}_{\mathrm{IO}_{2}}$ is to maintain adequate oxygenation and to minimize the exposure to hypoxemia, hyperoxemia, and oxygen. However, this is frequently not achieved during routine care, which increases the risks of associated side effects affecting the eye, lungs, and central nervous system. In the adult the primary goal is to avoid hypoxemia, but conventional methods of oxygen supplementation may fall short during periods of increased demand. On the other hand, there are growing concerns related to unnecessarily high $\mathrm{F}_{\mathrm{IO}_{2}}$ levels that increase the exposure to hyperoxemia and excessive oxygen use in settings where resources are limited. Systems for automated closed loop control of $\mathrm{F}_{\mathrm{IO}_{2}}$ have been developed for use in neonates and adults. This paper will give an overview of the rationale for the development of these systems, present the evidence, and discuss important advantages and limitations. Key words: oxygen; $F_{I O}$; hypoxemia; hyperoxemia; closed loop control. [Respir Care 2013;58(1):151-159. (C) 2013 Daedalus Enterprises]
\end{abstract}

\section{Introduction}

Oxygen therapy is extensively used in neonatal and adult intensive care, during pre-hospital transport, and at home in patients with chronic respiratory insufficiency. In the neonatal population, oxygen supplementation is essential for the survival of newborns in respiratory failure, and the

The authors are affiliated with the Division of Neonatology, Department of Pediatrics, University of Miami Miller School of Medicine, Miami, Florida.

Dr Claure presented a version of this paper at the 50th RESPIRATORY CARE Journal Conference, "Oxygen," held April 13-14, 2012, in San Francisco, California. need for supplemental oxygen is particularly frequent and prolonged among premature infants. In this population, the need for supplemental oxygen can extend from the initial

\footnotetext{
The authors have a patent on a closed loop oxygen system discussed herein. The University of Miami is the assignee for that patent and has a licensing agreement with CareFusion, which provided support for studies of the system.

Correspondence: Nelson Claure MSc PhD, Division of Neonatology, Department of Pediatrics, University of Miami Miller School of Medicine, PO Box 016960, R-131, Miami FL 33101. E-mail: nclaure@ miami.edu.
}

DOI: $10.4187 /$ respcare.01955 
stages of respiratory failure and convalescence to a more chronic dependence. In premature infants, excessive and prolonged oxygen supplementation has been associated with systemic oxidative damage and long-term complications affecting the eye, lungs, and central nervous system. ${ }^{1-4}$ On the other hand, insufficient oxygenation has also been associated with detrimental effects on the brain, pulmonary vasculature, patency of the ductus arteriosus, and other organs and tissues. ${ }^{5-11}$ Of greater concern is the possible influence of hypoxemia on mortality, as indicated years ago by the increase in mortality after curtailment of the use of oxygen, ${ }^{12-14}$ and more recently by trials showing increased mortality when targeting lower oxygenation to prevent the occurrence of retinopathy of prematurity and bronchopulmonary dysplasia. ${ }^{15,16}$

In order to reduce the risk of complications, the goal during manual control of the $\mathrm{F}_{\mathrm{IO}_{2}}$ in preterm infants is to maintain adequate oxygenation and minimize the exposure to hypoxemia, hyperoxemia, and oxygen. For this, arterial oxygen saturation is most commonly monitored by pulse oximetry $\left(\mathrm{S}_{\mathrm{pO}_{2}}\right)$ and $\mathrm{F}_{\mathrm{IO}_{2}}$ is titrated to maintain $\mathrm{S}_{\mathrm{pO}_{2}}$ within a clinically intended range. However, it has been shown that preterm infants spend approximately half of the time within the clinically intended range of $\mathrm{S}_{\mathrm{pO}_{2}}$, and more than one third of the time above this range during routine neonatal intensive care. ${ }^{17}$ Maintenance of $\mathrm{S}_{\mathrm{pO}_{2}}$ within the intended range is affected by the infant's respiratory instability, leading to frequent fluctuations in $\mathrm{S}_{\mathrm{pO}_{2}}$, to limitations in staff availability to respond to $\mathrm{S}_{\mathrm{pO}_{2}}$, and to tolerance of high $\mathrm{S}_{\mathrm{pO}_{2}}$ levels by the clinical staff. ${ }^{18,19}$ In order to overcome these limitations, improve maintenance of target range of $\mathrm{S}_{\mathrm{pO}_{2}}$, and minimize hyperoxemia, hypoxemia, and exposure to oxygen, systems of automated control of $\mathrm{F}_{\mathrm{IO}_{2}}$ have been developed for use in this population.

Oxygen supplementation is widely used in adult intensive care patients and during pre-hospital transport. In these patients the primary goal of oxygen therapy is the avoidance of hypoxemia, and the use of oxygen is quite liberal, because the risks of side effects associated with hyperoxemia or exposure to high $\mathrm{F}_{\mathrm{IO}_{2}}$ are generally considered to be small. There are, however, emerging concerns, including the association between both hyperoxemia and hypoxemia, with increased risk of death post cardiac arrest $^{20}$ and increased death or worse outcome in severe head trauma. ${ }^{21}$ Clinicians suggest potential benefits of $\mathrm{F}_{\mathrm{IO}_{2}}$ titration in lieu of a continuously high $\mathrm{F}_{\mathrm{IO}_{2}}$, independent of the arterial oxygen levels, ${ }^{22,23}$ and potential risks due to masking of the onset of worsening in lung function by hyperoxemia. ${ }^{24}$ Also, optimal use of oxygen during air or ground pre-hospital transport is important because oxygen resources may be limited. ${ }^{25}$

Prolonged oxygen supplementation is common in adult patients with COPD. In these patients supplemental oxygen is adjusted to maintain adequate oxygenation, but con- ventional oxygen delivery methods may fall short during periods of increased demand, when patient activity increases. Consumption of oxygen resources is a concern in these patients because oxygen delivery methods are designed to facilitate patient mobility. ${ }^{20}$

Based on these concerns, and with the goal of balancing the maintenance of adequate oxygenation with a rational use of resources, systems of automated closed loop control of $\mathrm{F}_{\mathrm{IO}_{2}}$ for adult patients have recently been developed.

\section{Systems of Closed Loop $\mathrm{F}_{\mathrm{IO}_{2}}$ Control}

Closed loop $\mathrm{F}_{\mathrm{IO}_{2}}$ control systems available for clinical or experimental use generally consist of an oxygenation monitoring device (eg, pulse oximeter), gas delivery device (eg, ventilator or cannula), and an algorithm that determines the timing and magnitude of the $\mathrm{F}_{\mathrm{IO}_{2}}$ adjustments.

\section{Oxygenation Monitoring}

Over the years, closed loop $\mathrm{F}_{\mathrm{IO}_{2}}$ systems for neonates and adults have utilized various methods, including indwelling $\mathrm{P}_{\mathrm{aO}_{2}}$ electrodes, transcutaneous $\mathrm{P}_{\mathrm{O}_{2}}$ electrodes $\left(\mathrm{P}_{\mathrm{tcO}_{2}}\right)$, or arterial oxygen saturation by pulse oximetry $\left(\mathrm{S}_{\mathrm{pO}_{2}}\right)$. A key requirement for the monitoring method used in a closed loop $\mathrm{F}_{\mathrm{IO}_{2}}$ system is the ability to provide information on the oxygenation status on a continuous basis, throughout the entire duration of the oxygen supplementation.

The use of indwelling $\mathrm{P}_{\mathrm{aO}}$ electrodes for closed loop $\mathrm{F}_{\mathrm{IO}_{2}}$ control is limited by the need of an invasive catheter in place. In neonates, invasive catheters are used during the acute phase of respiratory failure, but their use declines beyond this phase. $\mathrm{P}_{\mathrm{tcO}_{2}}$ electrodes require frequent calibration, and their accuracy depends on electrode temperature and perfusion. Hence, frequent changes in application site are required to avoid thermal skin injury in the preterm neonate. More recently, $\mathrm{S}_{\mathrm{pO}_{2}}$ has become the preferred method for continuous oxygenation monitoring in neonatal and adult intensive care. This is primarily due to its noninvasiveness and a simple, calibration-free setup. The continuous availability of $\mathrm{S}_{\mathrm{pO}_{2}}$ makes this method suitable for use in closed loop $\mathrm{F}_{\mathrm{IO}_{2}}$ control systems.

\section{Control Algorithms and Oxygen Delivery Devices}

Systems for closed loop $\mathrm{F}_{\mathrm{IO}_{2}}$ control are based on algorithms that determine the timing, magnitude, and frequency of each adjustment to keep $\mathrm{S}_{\mathrm{pO}_{2}}$ at the target level or range set by the clinician. The measured $\mathrm{S}_{\mathrm{pO}_{2}}$ is continuously or intermittently compared to the set target, and the $\mathrm{F}_{\mathrm{IO}_{2}}$ adjustments made by the algorithm are inversely related to their difference. These algorithms may also in- 
corporate adjustments in $\mathrm{F}_{\mathrm{IO}_{2}}$ based on trend data or the duration of the out of range fluctuation in $\mathrm{S}_{\mathrm{pO}_{2}}$.

The timing, magnitude, and frequency of adjustment determine the type of response to the changes in $\mathrm{S}_{\mathrm{pO}_{2}}$. These characteristics in the algorithms are tuned to meet the desired objectives for which the system is developed, and therefore define the applicability to different patient groups and the types of fluctuations it is capable of responding to. For instance, a system designed to respond only to slow changing fluctuations in $\mathrm{S}_{\mathrm{pO}_{2}}$ is unlikely to provide a timely response during acute and rapid changes in $\mathrm{S}_{\mathrm{pO}_{2}}$.

The response to an episode of hypoxemia must be adequate to assist in the recovery, but without producing a rebound hyperoxemia or overshoot. For this, optimization of the timing of the automatic increase in $\mathrm{F}_{\mathrm{IO}_{2}}$ when hypoxemia is detected, and the timing when $\mathrm{F}_{\mathrm{IO}_{2}}$ is brought back to baseline after the hypoxemia resolves are both important. A delayed increase in $\mathrm{F}_{\mathrm{IO}_{2}}$ when $\mathrm{S}_{\mathrm{pO}_{2}}$ is trending upwards is likely to result in overshoot into hyperoxemia, while a delayed return of $\mathrm{F}_{\mathrm{IO}_{2}}$ to baseline can prolong its duration.

Beat to beat $\mathrm{S}_{\mathrm{pO}_{2}}$ values are generally averaged over a running window before they are read by the closed loop algorithm. Long averaging windows attenuate the effects of short fluctuations in $\mathrm{S}_{\mathrm{pO}_{2}}$, but they also influence the response of the system. While on one hand, avoiding a response to short lived fluctuations is desirable, delayed or out of phase responses due to long averaging windows that do not reflect the true rate of change in $\mathrm{S}_{\mathrm{pO}_{2}}$ may also be counterproductive. A delayed increase in $\mathrm{F}_{\mathrm{IO}_{2}}$ because of late detection may prolong hypoxemia, while a delayed return of $\mathrm{F}_{\mathrm{IO}_{2}}$ to baseline after hypoxemia has actually resolved may lead to hyperoxemia.

Gas delivery devices used in closed loop $\mathrm{F}_{\mathrm{IO}_{2}}$ systems include mechanical ventilators, nasal CPAP devices, nasal cannula devices, and head boxes (also known as hoods). In ventilators and head boxes the air-oxygen mixture is done with blenders that should be sufficiently precise and sturdy to withstand the greater number of small changes required by automatic systems. In nasal cannula systems, the mixing of gases can be achieved by air-oxygen blenders or by modulating the infusion of oxygen to the inspired gas supply. Depending on the intended goal and type of patient, closed loop $\mathrm{F}_{\mathrm{IO}_{2}}$ systems may require certain flow rates to produce the changes in the inspired gas within a pre-defined time to achieve a desired effect. Delays in gas mixing may produce out of phase responses between the measured changes in $\mathrm{S}_{\mathrm{pO}_{2}}$ and the actual change in $\mathrm{F}_{\mathrm{IO}_{2}}$ received by the patient.

The design of closed loop $\mathrm{F}_{\mathrm{IO}_{2}}$ systems aimed at responding to hypoxemia events encounters a dilemma when determining the most adequate response when the measured hypoxemia by $\mathrm{S}_{\mathrm{pO}_{2}}$ is associated with motion artifact or poor signal quality. This involves the risk of unnecessary oxygen exposure if the measured hypoxemia is due to artifact, versus the risk of exposure to hypoxemia if this is a true hypoxemia event that is accompanied or triggered by patient activity. Avoidance of unnecessary oxygen exposure is desirable, but lack of response during a true event of hypoxemia may have acute consequences. A safe approach during automated $\mathrm{F}_{\mathrm{IO}_{2}}$ control is to respond to hypoxemia even if artifact is suspected and to alert the caregiver of the condition for evaluation.

Periods of missing $\mathrm{S}_{\mathrm{pO}_{2}}$ measurements due to extremely low signal quality or "drop-outs" can occur during patient activity, decreased perfusion, or probe disconnection. The criteria utilized by closed loop $\mathrm{F}_{\mathrm{IO}_{2}}$ systems to adopt a fall back state and the $\mathrm{F}_{\mathrm{IO}_{2}}$ to be set are important. The fall back $\mathrm{F}_{\mathrm{IO}_{2}}$ can be set by the clinician or by the algorithm based on recently supplied $\mathrm{F}_{\mathrm{IO}_{2}}$ levels. The selection of the fall back $\mathrm{F}_{\mathrm{IO}_{2}}$ should consider if hypoxemia can be temporally associated with patient activity and therefore go undetected during "drop outs" caused by motion artifact.

\section{Effects of Closed Loop $\mathrm{F}_{\mathrm{IO}_{2}}$ on Oxygenation, Oxygen Exposure, and Resource Utilization}

\section{In the Neonate}

Multiple studies have compared the efficacy of closed loop $\mathrm{F}_{\mathrm{IO}_{2}}$ systems to manual adjustments in maintaining oxygenation targets. ${ }^{26-35}$ These studies have utilized different modes of manual $\mathrm{F}_{\mathrm{IO}_{2}}$ adjustment for comparison, including the conventional routine care and more ideal modes consisting of a caregiver fully dedicated to the titration of $\mathrm{F}_{\mathrm{IO}_{2}}$. In these studies, automated $\mathrm{F}_{\mathrm{IO}_{2}}$ control systems were consistently more effective than manual $\mathrm{F}_{\mathrm{IO}_{2}}$ control during routine care in maintaining the oxygenation targets and were similar or better than a fully dedicated caregiver (Table 1).

It is important to note in these studies that closed loop $\mathrm{F}_{\mathrm{IO}_{2}}$ systems were evaluated in different groups of infants: those receiving invasive mechanical ventilation, nasal CPAP, or oxygen by hood. The studied populations also varied in regards to the frequency and severity of the fluctuations in oxygenation. Infants with frequent episodes of hypoxemia are the most challenging group of infants for the clinical staff and an automated system. An example is shown in Figure 1, where recordings of $\mathrm{S}_{\mathrm{pO}_{2}}$ and $\mathrm{F}_{\mathrm{IO}_{2}}$ illustrate the response of the automatic system and the substantial work load involved in manual titration of $\mathrm{F}_{\mathrm{IO}_{2}}$. The consistency in the findings of improved maintenance of the oxygenation target across these different patient groups provides proof of principle and attests to the feasibility of this approach in the care of the general preterm infant population. 
Table 1. Maintenance of the Oxygenation Target in Neonates

\begin{tabular}{|c|c|c|c|c|c|c|c|c|c|}
\hline \multirow{2}{*}{ First Author } & \multirow{2}{*}{ Year } & \multirow{2}{*}{ Support } & \multirow{2}{*}{ Monitor } & \multirow{2}{*}{ Target } & \multicolumn{3}{|c|}{ \% Time Within Target } & \multicolumn{2}{|c|}{$\begin{array}{c}\text { Manual } \mathrm{F}_{\mathrm{IO}_{2}} \text { Changes } \\
\text { Per Hour }\end{array}$} \\
\hline & & & & & Closed Loop & Manual & Manual Mode & Closed Loop & Manual \\
\hline Beddis $^{26}$ & 1979 & MV, CPAP, Hood & Indwelling $\mathrm{P}_{\mathrm{aO}_{2}}$ & $55-80 \mathrm{~mm} \mathrm{Hg}$ & 88 & 72 & Routine & ND & ND \\
\hline Dugdale $^{27}$ & 1988 & Hood & Indwelling $\mathrm{P}_{\mathrm{aO}_{2}}$ & $68-83 \mathrm{~mm} \mathrm{Hg}$ & 75 & 45 & Routine & ND & 0.5 \\
\hline Bhutani $^{28}$ & 1992 & Hood & $\mathrm{S}_{\mathrm{pO}_{2}}$ & $94-96 \%$ & 81 & $\begin{array}{l}54 \\
69\end{array}$ & $\begin{array}{l}\text { Routine } \\
\text { Dedicated }\end{array}$ & ND & $\begin{array}{c}2-3 \\
12-30\end{array}$ \\
\hline Morozoff ${ }^{29}$ & 1992 & MV & $\mathrm{S}_{\mathrm{pO}_{2}}$ & $92 \%$ & $\begin{array}{c}\downarrow \text { standard } \\
\text { deviation in } 6 / 8\end{array}$ & & Routine & 1 per 2 tests & ND \\
\hline Morozoff $^{31}$ & 2009 & MV & $\mathrm{S}_{\mathrm{pO}_{2}}$ & $90-95 \%$ & 50 & 39 & Routine & 1.0 & 8.1 \\
\hline $\operatorname{Sun}^{30}$ & 1997 & MV & $\mathrm{S}_{\mathrm{pO}_{2}}$ & Set $\pm 3 \%$ & 72 & 58 & Routine & ND & ND \\
\hline Claure $^{32}$ & 2001 & MV & $\mathrm{S}_{\mathrm{pO}_{2}}$ & $88-96 \%$ & 75 & 66 & Dedicated & 0 & 29 \\
\hline Urschitz $^{33}$ & 2004 & CPAP & $\mathrm{S}_{\mathrm{pO}_{2}}$ & $87-96 \%$ & 91 & $\begin{array}{l}82 \\
91\end{array}$ & $\begin{array}{l}\text { Routine } \\
\text { Dedicated }\end{array}$ & 0.3 & $\begin{array}{l}3.0 \\
7.7\end{array}$ \\
\hline Morozoff $^{31}$ & 2009 & MV & $\mathrm{S}_{\mathrm{pO}_{2}}$ & $90-96 \%$ & 73 & 57 & Routine & 0.2 & 3.7 \\
\hline Claure $^{34}$ & 2009 & MV & $\mathrm{S}_{\mathrm{pO}_{2}}$ & $88-95 \%$ & 58 & 42 & Routine & 1.8 & 8.5 \\
\hline Claure $^{35}$ & 2011 & MV & $\mathrm{S}_{\mathrm{pO}_{2}}$ & $87-93 \%$ & 40 & 32 & Routine & 0.4 & 4.7 \\
\hline
\end{tabular}

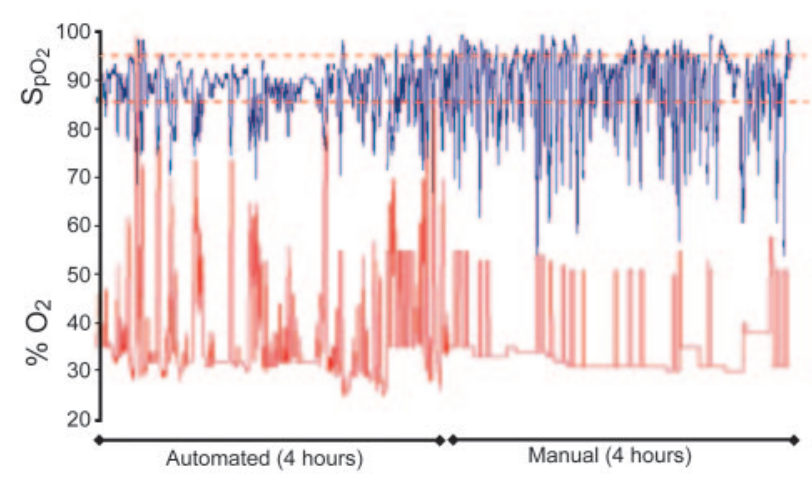

Fig. 1. Recordings of $\mathrm{S}_{\mathrm{pO}_{2}}$ and $\mathrm{F}_{\mathrm{IO}_{2}}$ during 4 hours of automatic and manual adjustment of $\mathrm{F}_{\mathrm{IO}_{2}}$ from an infant who presented with frequent episodes of hypoxemia illustrate the response of the automatic system to maintain $\mathrm{S}_{\mathrm{pO}_{2}}$ within the target range (dashed lines) and the effort involved in manual titration of $\mathrm{F}_{\mathrm{IO}_{2}}$.

The improved maintenance of the oxygenation targets was largely the result of a reduction in the time spent in hyperoxemia (Table 2), which was more evident in studies comparing closed loop $\mathrm{F}_{\mathrm{IO}_{2}}$ to manual adjustments during routine care. ${ }^{34,35}$ These findings also reflected the tolerance of high $\mathrm{S}_{\mathrm{pO}_{2}}$ levels by the clinical staff during routine care. In contrast, in studies comparing closed loop $\mathrm{F}_{\mathrm{IO}_{2}}$ to a fully dedicated nurse who was attentive to avoid hyperoxemia, the improved maintenance of the oxygenation targets was the result of a combined reduction in the time spent with $\mathrm{S}_{\mathrm{pO}_{2}}$ above and below the target range. ${ }^{32}$ Also shown in Table 2 is the reduction in $\mathrm{F}_{\mathrm{IO}_{2}}$ achieved by closed loop $\mathrm{F}_{\mathrm{IO}_{2}}$ systems. A more effective and consistent reduction in $\mathrm{F}_{\mathrm{IO}_{2}}$ may be beneficial in premature infants at risk of oxidative lung injury. Figure 2 illustrates with 24 hour data from Claure et $\mathrm{al}^{35}$ how the clinical staff maintained $\mathrm{S}_{\mathrm{pO}_{2}}$ near the upper limit of the target range, while the automatic system shifted $\mathrm{S}_{\mathrm{pO}_{2}}$ toward the center of the target range over time. This was accompanied by a consistent reduction of $\mathrm{F}_{\mathrm{IO}_{2}}$ soon after the infants were switched to the automatic system.

The proportion of time infants spent with oxygenation levels below the target in the different studies was not reduced by closed loop $\mathrm{F}_{\mathrm{IO}_{2}}$ as consistently as the reduction in hyperoxemia (Table 3). Although these observations seem at first counterintuitive, they underline the fact that closed loop systems can respond to the occurrence of spells of decreased $\mathrm{S}_{\mathrm{pO}_{2}}$, but they are ineffective in their prevention. Also, because hypoxemia spells in preterm infants are largely triggered by changes in ventilation and lung volume, the automatic increase in $\mathrm{F}_{\mathrm{IO}_{2}}$ can attenuate the severity or duration of the episode, but it is unlikely to produce an immediate resolution of the episode of hypoxemia. ${ }^{35}$ In studies focused on preterm infants who present with frequent hypoxemia episodes, there was an increased number of mild episodes during closed loop $\mathrm{F}_{\mathrm{IO}_{2}}$ control, in comparison to manual adjustments during routine care. This difference was largely related to the maintenance of relatively high basal $\mathrm{S}_{\mathrm{pO}_{2}}$ levels by the staff trying to prevent the spells of hypoxemia. This preventive strategy was only partially effective in preventing hypoxemia episodes, but increased the exposure to oxygen. In contrast, closed loop $\mathrm{F}_{\mathrm{IO}_{2}}$ control was more effective in reducing the number of the more severe and prolonged episodes of hypoxemia. 
Table 2. Oxygenation Above the Oxygenation Target and $\mathrm{F}_{\mathrm{IO}_{2}}$ in Neonates

\begin{tabular}{|c|c|c|c|c|c|c|c|c|}
\hline \multirow{2}{*}{ First Author } & \multirow{2}{*}{ Year } & \multirow{2}{*}{ Monitor } & \multirow{2}{*}{ Range } & \multicolumn{3}{|c|}{$\%$ Time in Range } & \multicolumn{2}{|c|}{$\mathrm{F}_{\mathrm{IO}_{2}}$} \\
\hline & & & & Closed Loop & Manual & Manual Mode & Closed Loop & Manual \\
\hline Beddis $^{26}$ & 1979 & Indwelling $\mathrm{P}_{\mathrm{aO}_{2}}$ & $>80 \mathrm{~mm} \mathrm{Hg}$ & 4.7 & 9.3 & Routine & ND & ND \\
\hline Dugdale $^{27}$ & 1988 & Indwelling $\mathrm{P}_{\mathrm{aO}_{2}}$ & $>83 \mathrm{~mm} \mathrm{Hg}$ & 11 & 13 & Routine & 0.45 & 0.44 \\
\hline Morozoff $^{29}$ & 1992 & $\mathrm{~S}_{\mathrm{pO}_{2}}$ & $>95 \%$ & 23 & 39 & Routine & ND & ND \\
\hline Claure $^{32}$ & 2001 & $\mathrm{~S}_{\mathrm{pO}_{2}}$ & $>96 \%$ & 10 & 15 & Dedicated & 0.34 & 0.34 \\
\hline Urschitz $^{33}$ & 2004 & $\mathrm{~S}_{\mathrm{pO}_{2}}$ & $>96 \%$ & $\sim 1.3^{*}$ & $\begin{array}{l}\sim 4.9^{*} \\
\sim 1.8^{*}\end{array}$ & $\begin{array}{l}\text { Routine } \\
\text { Dedicated }\end{array}$ & ND & ND \\
\hline Claure $^{34}$ & 2009 & $\mathrm{~S}_{\mathrm{pO}_{2}}$ & $\begin{array}{l}>95 \% \\
\geq 98 \%\end{array}$ & 9.3 & $\begin{array}{l}31 \\
16\end{array}$ & $\begin{array}{l}\text { Routine } \\
\text { Dedicated }\end{array}$ & 0.29 & 0.34 \\
\hline Claure $^{35}$ & 2011 & $\mathrm{~S}_{\mathrm{pO}_{2}}$ & $\begin{array}{l}>93 \% \text { with } \mathrm{F}_{\mathrm{IO}_{2}}>0.21 \\
>98 \% \text { with } \mathrm{F}_{\mathrm{IO}_{2}}>0.21\end{array}$ & $\begin{array}{l}21 \\
0.7\end{array}$ & $\begin{array}{l}37 \\
5.6\end{array}$ & $\begin{array}{l}\text { Routine } \\
\text { Dedicated }\end{array}$ & 0.32 & 0.37 \\
\hline
\end{tabular}

* Calculated from episode duration and frequency.

$\mathrm{MV}=$ mechanical ventilation

$\mathrm{ND}=$ no data available

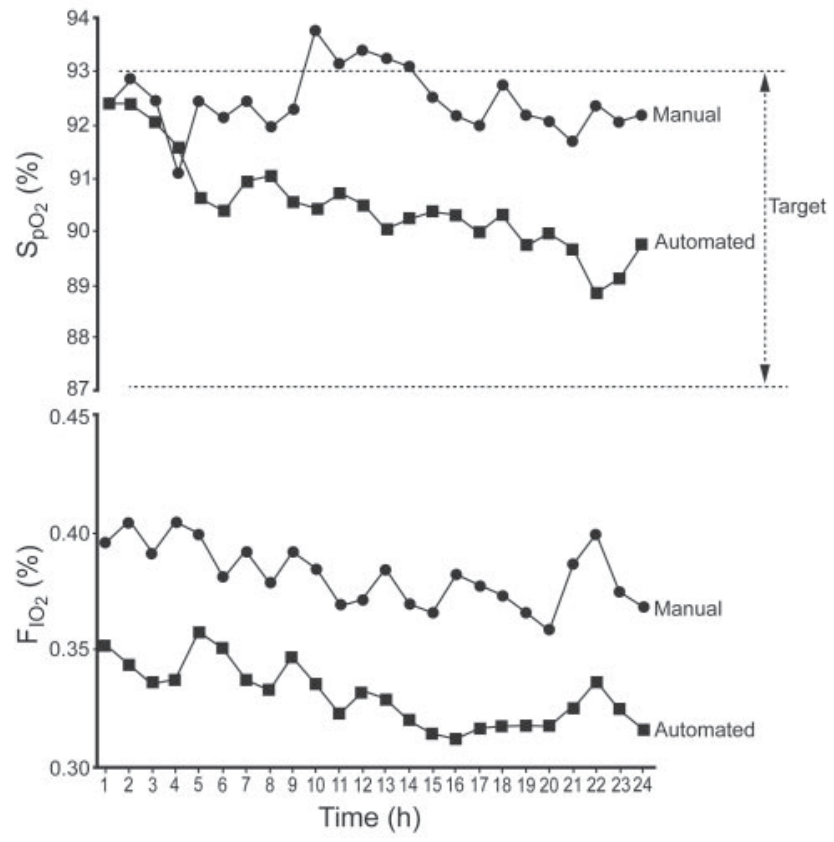

Fig. 2. Hourly median $\mathrm{S}_{\mathrm{pO}_{2}}$ and $\mathrm{F}_{\mathrm{IO}_{2}}$ values from 24 hour data from Claure et al35 illustrate maintenance of $\mathrm{S}_{\mathrm{pO}_{2}}$ near the upper limit of the target range by the clinical staff, while the automatic system shifted $\mathrm{S}_{\mathrm{pO}_{2}}$ toward the center of the range over time. $\mathrm{F}_{\mathrm{IO}_{2}}$ was lowered soon after the infants were switched to the automatic system and remained consistently below the levels provided by the clinical staff.

The improved maintenance of $\mathrm{S}_{\mathrm{pO}_{2}}$ targets by automatic $\mathrm{F}_{\mathrm{IO}_{2}}$ control was achieved in spite of a considerable effort of the clinical staff. $\mathrm{F}_{\mathrm{IO}_{2}}$ was adjusted by the staff an average 8.5 times per hour during day time, ${ }^{34}$ and 113 times during a 24 hour period. ${ }^{35}$ These findings suggest potential reductions in work load that may also enable a more effective use of the caregiver's effort toward the improvement of other areas of care.

\section{In the Adult}

Studies have compared multiple systems for automated control of $\mathrm{F}_{\mathrm{IO}_{2}}$ to the conventional modes of oxygen administration in mechanically ventilated trauma intensive care patients, and in COPD patients who receive long-term oxygen therapy during exercise and normal activity, as well as during induced hypoxemia in adult volunteers. ${ }^{36-39}$ In these studies (Table 4) closed loop $\mathrm{F}_{\mathrm{IO}_{2}}$ systems set to maintain $\mathrm{S}_{\mathrm{pO}_{2}}$ between $90 \%$ and $96 \%$ have consistently improved the maintenance of such range, compared to conventional care consisting of either a manually titrated or a constant oxygen supply. More importantly, these studies documented that automated closed loop control of $\mathrm{F}_{\mathrm{IO}_{2}}$ was more effective in reducing hypoxemia, which is the primary concern in these patients (Table 5). These findings suggest that the eventual benefits of closed loop $\mathrm{F}_{\mathrm{IO}_{2}}$ may be related not only to less hypoxemia, but also to facilitating increased activity levels in chronic patients who, without manual titration of the supplemental oxygen, would become hypoxemic.

These data confirmed that high $\mathrm{S}_{\mathrm{pO}_{2}}$ levels are common and prolonged, which involves considerable oxygen utilization (Table 6). The time spent with high $\mathrm{S}_{\mathrm{pO}_{2}}$ was consistently reduced by closed loop $\mathrm{F}_{\mathrm{IO}_{2}}$, compared to the conventional care, without leading to detrimental effects. These findings not only document the efficacy of closed loop $\mathrm{F}_{\mathrm{IO}_{2}}$ in these populations, but also suggest that hyperoxemia did not confer a tangible advantage in those patients. The observed oxygen resource savings may be appealing for applications such as transport or remote facilities where closed loop $\mathrm{F}_{\mathrm{IO}_{2}}$ systems may lead to a more 
Automated Closed Loop Control of Inspired Oxygen Concentration

Table 3. Oxygenation Below the Oxygenation Target in Neonates

\begin{tabular}{|c|c|c|c|c|c|c|}
\hline \multirow{2}{*}{ First Author } & \multirow{2}{*}{ Year } & \multirow{2}{*}{ Monitor } & \multirow{2}{*}{ Range } & \multicolumn{3}{|c|}{$\%$ Time in Range } \\
\hline & & & & Closed Loop & Manual & Manual Mode \\
\hline Beddis $^{26}$ & 1979 & Indwelling $\mathrm{P}_{\mathrm{aO}_{2}}$ & $<55 \mathrm{~mm} \mathrm{Hg}$ & 7.5 & 18.3 & Routine \\
\hline Dugdale $^{27}$ & 1988 & Indwelling $\mathrm{P}_{\mathrm{aO}_{2}}$ & $<68 \mathrm{~mm} \mathrm{Hg}$ & 15 & 42 & Routine \\
\hline Morozoff $^{29}$ & 1992 & $\mathrm{~S}_{\mathrm{pO}_{2}}$ & $<90 \%$ & 27 & 32 & Routine \\
\hline Claure $^{32}$ & 2001 & $\mathrm{~S}_{\mathrm{pO}_{2}}$ & $\begin{array}{l}<88 \% \\
<75 \%\end{array}$ & $\begin{array}{c}17 \\
0\end{array}$ & $\begin{array}{c}19 \\
0.35\end{array}$ & Dedicated \\
\hline Urschitz $^{33}$ & 2004 & $\mathrm{~S}_{\mathrm{pO}_{2}}$ & $<87 \%$ & $\sim 3.2^{*}$ & $\begin{array}{l}\sim 6.7^{*} \\
\sim 3.9^{*}\end{array}$ & $\begin{array}{l}\text { Routine } \\
\text { Dedicated }\end{array}$ \\
\hline Claure $^{34}$ & 2009 & $\mathrm{~S}_{\mathrm{pO}_{2}}$ & $\begin{array}{l}<88 \% \\
<75 \%\end{array}$ & $\begin{array}{l}33 \\
4.6\end{array}$ & $\begin{array}{l}27 \\
6.6\end{array}$ & Routine \\
\hline Claure $^{35}$ & 2011 & $\mathrm{~S}_{\mathrm{pO}_{2}}$ & $\begin{array}{l}<87 \% \\
<75 \%\end{array}$ & $\begin{array}{l}32 \\
4.7\end{array}$ & $\begin{array}{l}23 \\
5.4\end{array}$ & Routine \\
\hline
\end{tabular}

* Calculated from episode duration and frequency.

Table 4. Maintenance of the Oxygenation Target in Adults

\begin{tabular}{|c|c|c|c|c|c|c|c|}
\hline \multirow{2}{*}{ First Author } & \multirow{2}{*}{ Year } & \multirow{2}{*}{ Support } & \multirow{2}{*}{ Monitor } & \multirow{2}{*}{$\begin{array}{c}\text { Target } \\
(\%)\end{array}$} & \multicolumn{3}{|c|}{$\%$ Time Within Target } \\
\hline & & & & & Closed Loop & Manual & Manual Mode \\
\hline Johannigman $^{36}$ & 2009 & Mechanical ventilation, trauma, intensive care & $\mathrm{S}_{\mathrm{pO}_{2}}$ & $92-96$ & 83 & 33 & \\
\hline Cirio $^{37}$ & 2011 & Cannula, exercise test & $\mathrm{S}_{\mathrm{pO}_{2}}$ & 94 & ND & ND & \\
\hline Rice $^{38}$ & 2011 & Cannula, home activity & $\mathrm{S}_{\mathrm{pO}_{2}}$ & $\geq 90$ & ND & ND & \\
\hline Lellouche $^{39}$ & 2012 & Cannula, induced hypoxia & $\mathrm{S}_{\mathrm{pO}_{2}}$ & $92-96$ & 67 & $\begin{array}{l}37 \\
36\end{array}$ & $\begin{array}{l}\text { Constant } \mathrm{O}_{2} \\
\text { Air }\end{array}$ \\
\hline
\end{tabular}

$\overline{\mathrm{ND}}=$ no data available

Table 5. Oxygenation Below Target in Adults

\begin{tabular}{|c|c|c|c|c|c|c|c|}
\hline \multirow{2}{*}{ First Author } & \multirow{2}{*}{ Year } & \multirow{2}{*}{ Support } & \multirow{2}{*}{ Monitor } & \multirow{2}{*}{$\begin{array}{l}\text { Range } \\
(\%)\end{array}$} & \multicolumn{3}{|c|}{$\%$ Time in Range } \\
\hline & & & & & Closed Loop & Manual & Manual Mode \\
\hline Johannigman $^{36}$ & 2009 & Mechanical ventilation, trauma intensive care & $\mathrm{S}_{\mathrm{pO}_{2}}$ & $<88$ & 2.5 & 2.9 & \\
\hline Cirio $^{37}$ & 2011 & Cannula, exercise test & $\mathrm{S}_{\mathrm{pO}_{2}}$ & $<94$ & 19 & 38 & \\
\hline Rice $^{38}$ & 2011 & Cannula, home activity & $\mathrm{S}_{\mathrm{pO}_{2}}$ & $<88$ & 10 & $\begin{array}{l}19 \\
15\end{array}$ & $\begin{array}{l}\mathrm{O}_{2} \text { conserver } \\
\text { Constant flow }\end{array}$ \\
\hline Lellouche $^{39}$ & 2012 & Cannula, induced hypoxia & $\mathrm{S}_{\mathrm{pO}_{2}}$ & $<88$ & 0.4 & $\begin{array}{l}13 \\
34\end{array}$ & $\begin{array}{l}\text { Constant } \mathrm{O}_{2} \\
\text { Air }\end{array}$ \\
\hline
\end{tabular}

efficient oxygen utilization. Also important is the potential reduction in the effort required for manual adjustment of the inspired oxygen and better utilization of the staff.

New systems that combine automatic adjustments of ventilator parameters, such as minute ventilation and peak inspiratory pressure, in parallel to automatic adjustment of $\mathrm{F}_{\mathrm{IO}_{2}}$ and PEEP, have recently become available. ${ }^{40,41}$ Reports on the use of these systems in adult ventilated patients with acute lung injury and post-cardiac surgery indicate better maintenance of the target ranges of oxygenation and other physiologic targets, less hyper- oxemia, and reductions in $\mathrm{F}_{\mathrm{IO}_{2}}$. These more sophisticated systems also resulted in fewer manual interventions from the clinical team to adjust the ventilator settings.

\section{Important Considerations and Possible Disadvantages}

In both neonatal and adult populations the most important aspect to be considered by the clinician when determining the use of closed loop $\mathrm{F}_{\mathrm{IO}_{2}}$ is the target range of $\mathrm{S}_{\mathrm{pO}_{2}}$. In both populations the optimal range of $\mathrm{S}_{\mathrm{pO}_{2}}$ has not 
Automated Closed Loop Control of Inspired Oxygen Concentration

Table 6. Oxygenation Above Target and Consumption of Oxygen Resources in Adults

\begin{tabular}{|c|c|c|c|c|c|c|c|c|c|}
\hline \multirow{2}{*}{ First Author } & \multirow{2}{*}{ Year } & \multirow{2}{*}{ Support } & \multirow{2}{*}{ Monitor } & \multirow{2}{*}{ Range, $\%$} & \multicolumn{3}{|c|}{$\%$ Time in Range } & \multicolumn{2}{|c|}{ Oxygen resource use } \\
\hline & & & & & Closed Loop & Manual & Manual Mode & Closed Loop & Manual \\
\hline Johannigman $^{36}$ & 2009 & MV, trauma intensive care & $\mathrm{S}_{\mathrm{pO}_{2}}$ & $>96$ & $\sim 16$ & $\sim 65$ & & $40 \%$ less & \\
\hline Cirio $^{37}$ & 2011 & Cannula, exercise test & $\mathrm{S}_{\mathrm{pO}_{2}}$ & $>95$ & 19 & 38 & & ND & ND \\
\hline Rice $^{38}$ & 2011 & Cannula, home activity & $\mathrm{S}_{\mathrm{pO}_{2}}$ & $>95$ & 10 & $\begin{array}{l}41 \\
39\end{array}$ & $\begin{array}{l}\mathrm{O}_{2} \text { conserver } \\
\text { Constant flow }\end{array}$ & $10^{*}$ & $\begin{array}{l}3^{*} \\
1\end{array}$ \\
\hline Lellouche $^{39}$ & 2012 & Cannula, induced hypoxia & $\mathrm{S}_{\mathrm{pO}_{2}}$ & $>96$ & 15 & $\begin{array}{l}39 \\
4.1\end{array}$ & $\begin{array}{l}\text { Constant } \mathrm{O}_{2} \\
\text { Air }\end{array}$ & $1.0 \mathrm{~L} / \mathrm{min}$ & $1.5 \mathrm{~L} / \mathrm{min}$ \\
\hline
\end{tabular}

been clearly defined, and most of the currently recommended ranges may not truly represent the actual levels of $\mathrm{S}_{\mathrm{pO}_{2}}$. Although the primary benefit of closed loop systems may be given by the avoidance of the extreme ranges of $\mathrm{S}_{\mathrm{pO}_{2}}$, there may be important physiologic and clinical effects of specific target ranges that have not yet been determined. A more consistent maintenance of specific target ranges by automated systems may uncover effects that have not been previously documented. Hence, cautious selection of the target range is warranted, because any adverse or beneficial effect may not be attributable to the automated approach but to the better maintenance of such range.

Closed loop $\mathrm{F}_{\mathrm{IO}_{2}}$ systems are dependent on the reliability and accuracy of pulse oximetry. Although closed loop algorithms can validate the reliability of $\mathrm{S}_{\mathrm{pO}_{2}}$ and enter into fall back state, the clinician determining the use of closed loop $\mathrm{F}_{\mathrm{IO}_{2}}$ in an individual patient should apply the same or even stricter criteria as the one used routinely to monitor and assure the reliability of pulse oximetry in every patient.

Automated control of $\mathrm{F}_{\mathrm{IO}_{2}}$ provides a single parameter response to hypoxemia, whereas the caregiver response, if appropriate, would determine the mechanism producing hypoxemia, followed by the appropriate intervention. For instance, increased $\mathrm{F}_{\mathrm{IO}_{2}}$ may not be the most adequate response when the hypoxemia is due to hypoventilation. However, it should be noted that clinical staff frequently respond first by increasing $\mathrm{F}_{\mathrm{IO}_{2}}$ to attenuate the hypoxemia and then investigate the cause. The likely earlier automatic response could further attenuate the hypoxemia until the corrective intervention is done. Ventilation monitoring, assessment, and identification of the mechanism producing hypoxemia that should be part of the standard care must also be part of the care during automated control of $\mathrm{F}_{\mathrm{IO}_{2}}$. This is important, because one possible drawback of the use of automated $\mathrm{F}_{\mathrm{IO}_{2}}$ control systems is that they could inadvertently reduce the attentiveness of the caregiver and delay recognition of changes in respiratory function. To minimize this risk of masking an ongoing deterioration in respiratory function by the automatic increase in $\mathrm{F}_{\mathrm{IO}_{2}}$, closed loop $\mathrm{F}_{\mathrm{IO}_{2}}$ systems should warn of persistent increases in $\mathrm{F}_{\mathrm{IO}_{2}}$, even if $\mathrm{S}_{\mathrm{pO}_{2}}$ is within the target range in order to prompt assessment by the clinician. The occurrence of these unwanted effects has not yet been shown, but, nonetheless, adequate training and careful use of these systems are warranted.

\section{Summary}

In premature infants, important detrimental effects have been associated with insufficient oxygenation as well as hyperoxemia and excessive exposure to high $\mathrm{F}_{\mathrm{IO}_{2}}$ levels. These risks are increased because of the infant's respiratory instability and the limitations of conventional care in maintaining the target ranges of oxygenation. Available data indicate the feasibility of automated closed loop control of $\mathrm{F}_{\mathrm{IO}_{2}}$ in this population and suggest potential benefits by achieving a better oxygenation control while limiting oxygen exposure. The long-term effects of this approach in these population still need to be assessed.

In the adult, oxygen supplementation is primarily used to avoid hypoxemia, with generally little concern about hyperoxemia. This, however, is being increasingly challenged by concerns of the possible noxious effects of hyperoxemia. These concerns, along with the possible benefits of better oxygen utilization and reduced staff effort, have stimulated the development of automated $\mathrm{F}_{\mathrm{IO}_{2}}$ control systems that have shown promising results. These include better maintenance of the oxygenation targets, less hypoxemia and hyperoxemia, and reduced oxygen use. The long-term benefits of this approach in the adult population also need to be further explored.

Studies of automated control of $\mathrm{F}_{\mathrm{IO}_{2}}$ have also documented the potential for substantial reductions in work load. Therefore, the possibility exists that use of these systems may indirectly improve care by shifting the staff effort to other patient care functions. 


\section{Automated Closed Loop Control of InsPired Oxygen Concentration}

\section{REFERENCES}

1. Flynn JT, Bancalari E, Snyder ES, Goldbert RN, Feuer W, Cassady $\mathrm{J}$, et al. A cohort study of transcutaneous oxygen tension and the incidence and severity of retinopathy of prematurity. N Engl J Med 1992;326(16):1050-1054

2. Collins MP, Lorenz JM, Jetton JR, Paneth N. Hypocapnia and other ventilation-related risk factors for cerebral palsy in low birth weight infants. Pediatr Res 2001;50(6):712-719.

3. Askie LM, Henderson-Smart DJ, Irwig L, Simpson JM. Oxygensaturation targets and outcomes in extremely preterm infants. N Engl J Med 2003;349(10):959-967.

4. Supplemental therapeutic oxygen for prethreshold retinopathy of prematurity (STOP-ROP), a randomized, controlled trial. I: primary outcomes. Pediatrics 2000;105(2):295-310.

5. Skinner JR, Hunter S, Poets CF, Milligan DW, Southall D, Hey EN. Haemodynamic effects of altering arterial oxygen saturation in preterm infants with respiratory failure. Arch Dis Child Fetal Neonatal Ed 1999;80(2):F81-F87.

6. Noori S, Patel D, Friedlich P, Siassi B, Seri I, Ramanathan R. Effects of low oxygen saturation limits on the ductus arteriosus in extremely low birth weight infants. J Perinatol 2009;29(8):553-557.

7. Cassin S, Dawes GS, Mott JC, Ross BB, Strang LB. The vascular resistance of the foetal and newly ventilated lung of the lamb. J Physiol 1964;171:61-79.

8. Halliday HL, Dumpit FM, Brady JP. Effects of inspired oxygen on echocardiographic assessment of pulmonary vascular resistance and myocardial contractility in bronchopulmonary dysplasia. Pediatrics 1980;65(3):536-540.

9. Abman SH, Wolfe RR, Accurso RJ, Koops BL, Bowman CM, Wiggins JW. Pulmonary vascular response to oxygen in infants with severe bronchopulmonary dysplasia. Pediatrics 1985;75(1):80-84.

10. Teague WG, Pian MS, Heldt GP, Tooley WH. An acute reduction in the fraction of inspired oxygen increases airway constriction in infants with chronic lung disease. Am Rev Respir Dis 1988;137(4): 861-865.

11. Tay-Uyboco JS, Kwiatkowski K, Cates DB, Kavanagh L, Rigatto H. Hypoxic airway constriction in infants of very low birth weight recovering from moderate to severe bronchopulmonary dysplasia. J Pediatr 1989;115(3):456-459.

12. Cross KW. Cost of preventing retrolental fibroplasia? Lancet 1973; 2(7835):954-956

13. Avery ME. Recent increase in mortality from hyaline membrane disease. J Pediatr 1960;57:553-559.

14. Bolton DP, Cross KW. Further observations on cost of preventing retrolental fibroplasia. Lancet 1974;1(7855):445-448.

15. SUPPORT Study Group; Eunice Kennedy Shriver NICHD Neonatal Research Network; Carlo WA, Finer NN, Walsh MC, Rich W, Gantz MG, Laptook AR, et al. Target ranges of oxygen saturation in extremely preterm infants. N Engl J Med 2010;362(21): 1959-1969.

16. Stenson B, Brocklehurst P, Tarnow-Mordi W; U.K. BOOST II Trial; Australian BOOST II Trial; New Zealand BOOST II Trial. Increased 36-week survival with high oxygen saturation target in extremely preterm infants. N Engl J Med 2011;364(17):1680-1682.

17. Hagadorn JI, Furey AM, Nghiem TH, Schmid CH, Phelps DL, Pillers DA, Cole $\mathrm{CH}$. Achieved versus intended pulse oximeter saturation in infants born less than 28 weeks' gestation: the AVIOx study. Pediatrics 2006;118(4):1574-1582.

18. Sink DW, Hope SA, Hagadorn JI. Nurse:patient ratio and achievement of oxygen saturation goals in premature infants. Arch Dis Child Fetal Neonatal Ed 2011;96(2):F93-F98
19. Clucas L, Doyle LW, Dawson J, Donath S, Davis PG. Compliance with alarm limits for pulse oximetry in very preterm infants. Pediatrics 2007;119(6): 1056-1060.

20. Croxton TL, Bailey WC. Long-term oxygen treatment in chronic obstructive pulmonary disease: recommendations for future research: an NHLBI workshop report. Am J Respir Crit Care Med 2006; 174(4):373-378.

21. Kilgannon JH, Jones AE, Shapiro NI, Angelos MG, Milcarek B, Hunter K, et al; Emergency Medicine Shock Research Network (EMShockNet) Investigators. Association between arterial hyperoxia following resuscitation from cardiac arrest and in-hospital mortality. JAMA 2010;303(21):2165-2171.

22. Davis DP, Meade W, Sise MJ, Kennedy F, Simon F, Tominaga G, et al. Both hypoxemia and extreme hyperoxemia may be detrimental in patients with severe traumatic brain injury. J Neurotrauma 2009; 26(12):2217-2223

23. de Graaff AE, Dongelmans DA, Binnekade JM, de Jonge E. Clinicians' response to hyperoxia in ventilated patients in a Dutch ICU depends on the level of $\mathrm{F}_{\mathrm{IO}_{2}}$. Intensive Care Med 2011;37(1):46-51.

24. Branson RD, Robinson BR. Oxygen: when is more the enemy of good? Intensive Care Med 2011;37(1):1-3

25. Stockinger ZT, Mcswain NE Jr. Prehospital supplemental oxygen in trauma patients: its efficacy and implications for military medical care. Mil Med 2004;169(8):609-612.

26. Beddis IR, Collins P, Levy NM, Godfrey S, Silverman M. New technique for servo-control of arterial oxygen tension in preterm infants. Arch Dis Child 1979;54(4):278-280.

27. Dugdale RE, Cameron RG, Lealman GT. Closed-loop control of the partial pressure of arterial oxygen in neonates. Clin Physics Physiol Meas 1988;9(4):291-305.

28. Bhutani VK, Taube JC, Antunes MJ, Delivoria-Papadopoulos M. Adaptive control of the inspired oxygen delivery to the neonate. Pediatr Pulmonol 1992;14(2):110-117.

29. Morozoff PE, Evans RW. Closed-loop control of $\mathrm{S}_{\mathrm{aO}_{2}}$ in the neonate. Biomed Instrum Technol 1992;26(2):117-123.

30. Sun Y, Kohane IS, Stark AR. Computer-assisted adjustment of inspired oxygen concentration improves control of oxygen saturation in newborn infants requiring mechanical ventilation. J Pediatr 1997; 131(5):754-756.

31. Morozoff EP, Smyth JA. Evaluation of three automatic oxygen therapy control algorithms on ventilated low birth weight neonates. Conf Proc IEEE Eng Med Biol Soc 2009;2009:3079-3082.

32. Claure N, Gerhardt T, Everett R, Musante G, Herrera C, Bancalari E. Closed-loop controlled inspired oxygen concentration for mechanically ventilated very low birth weight infants with frequent episodes of hypoxemia. Pediatrics 2001;107(5):1120-1124.

33. Urschitz MS, Horn W, Seyfang A, Hallenberger A, Herberts T, Miksch S, et al. Automatic control of the inspired oxygen fraction in preterm infants: a randomized crossover trial. Am J Respir Crit Care Med 2004;170(10):1095-1100.

34. Claure N, D'Ugard C, Bancalari E. Automated adjustment of inspired oxygen in preterm infants with frequent fluctuations in oxygenation: a pilot clinical trial. J Pediatr 2009;155(5):640-645.

35. Claure N, Bancalari E, D’Ugard C, Nelin L, Stein M, Ramanathan R, et al. Multicenter crossover study of automated adjustment of inspired oxygen in mechanically ventilated preterm infants. Pediatrics 2011;127(1):e76-e83.

36. Johannigman JA, Branson R, Lecroy D, Beck G. Autonomous control of inspired oxygen concentration during mechanical ventilation of the critically injured trauma patient. J Trauma 2009;66(2):386-392.

37. Cirio S, Nava S. Pilot study of a new device to titrate oxygen flow in hypoxic patients on long-term oxygen therapy. Respir Care 2011; 56(4):429-434. 
38. Rice KL, Schmidt MF, Buan JS, Lebahn F, Schwarzock TK. AccuO oximetry-driven oxygen-conserving device versus fixed-dose oxygen devices in stable COPD patients. Respir Care 2011;56(12): 1901-1905.

39. Lellouche F, L'Her E. Automated oxygen flow titration to maintain constant oxygenation. Respir Care 2012;57(8):1254-1262.

40. Lellouche F, Bouchard PA, Laubscher T, Blackburn S, L'Her E, Wysocki M. Prospective randomized controlled study comparing conventional ventilation versus a fully closed-loop ventilation (IntelliVent) in post cardiac surgery ICU patients. Intensive Care Med 2010;36(Suppl):S752.

41. Arnal JM, Wysocki M, Novotni D, Demory D, Lopez R, Donati S, et al. Safety and efficacy of a fully closed-loop control ventilation (IntelliVent-ASV) in sedated ICU patients with acute respiratory failure: a prospective randomized crossover study. Intensive Care Med 2012;38(5):781-787.

\section{Discussion}

Kallet: One thing just occurred to me, at least in terms of the adult. As a clinician, if it's busy in the unit and I have someone who may be on $60 \%$ or $70 \% \mathrm{O}_{2}$ with a stable $\mathrm{S}_{\mathrm{pO}_{2}}$, I might say to myself I really don't have time to wean them, because if I do and they become unstable, I'm not sure I can get back to them quickly enough. One of the potential implications for adults is that, with automatic titration, work load and acuity will have less of an impact if you have an automatic titration and a way to monitor how stable they are at the lower $\mathrm{F}_{\mathrm{IO}_{2}}$. It might actually facilitate weaning.

The other thing is that more severely ill patients with ARDS may have borderline $\mathrm{P}_{\mathrm{aO}}$, but if you titrate them down in $5 \%$ steps, they actually maintain saturation. So I think there's a psychological component to this. The clinician may be reluctant to wean the $\mathrm{F}_{\mathrm{IO}_{2}}$ in a tenuous patient they're not confident will do $\mathrm{OK}$ with the change. There might be something very nice about an automatically titrated system that may affect outcomes.

Claure: Very important point. I agree. There are additional potential benefits in intensive care in general and across different patient groups. It might have indirect benefits because of the more consistent approach, not only in responding to hypoxemia, but in weaning $\mathrm{F}_{\mathrm{IO}_{2}}$ that may exceed what is necessary for a given patient.

MacIntyre: I was thinking of this from the adult perspective as well, and I can see situations where if you have hypoxemia, and your normal response is to adjust the $\mathrm{F}_{\mathrm{IO}_{2}}$, this system could be very useful. A classic example would be in the home, where you increase your activities or exercise and you have an $\mathrm{F}_{\mathrm{IO}_{2}}$ response situation. I'm having a lot of difficulty imagining this in the ICU, because there are many other manipulations you may want. For instance, you may want to adjust PEEP or assess suctioning needs or minute ventilation or hemodynamics, and having a system that's going to be adjusting the $\mathrm{F}_{\mathrm{IO}_{2}}$ to keep the $\mathrm{S}_{\mathrm{pO}_{2}}$ alarm from going off just seems a little simplistic for me right now. Are there ways of using this kind of feedback system and incorporating a PEEP $/ \mathrm{F}_{\mathrm{IO}_{2}}$ algorithm so it's not just $\mathrm{F}_{\mathrm{IO}_{2}}$ adjustments?

Claure: This is a very important issue and relevant not only in adults. A change in oxygen may not be the most appropriate response. The patient may benefit from addressing the root cause of the hypoxemia. Unfortunately, it does not always happen, and the first response is often to increase the $\mathrm{O}_{2}$, which is followed by assessment. Many times ventilation parameters are not monitored or assessed.

There are systems that adjust PEEP and $\mathrm{F}_{\mathrm{IO}_{2}}$ simultaneously in adults and pediatric patients. ${ }^{1,2}$ Systems developed for neonates can increase the mandatory rate of the ventilator in the event of hypoxemia. ${ }^{3}$ There is a risk that closed-loop $\mathrm{F}_{\mathrm{IO}_{2}}$ may reduce attentiveness, but there are methods the staff can use to monitor ventilation and tidal volume. Alarm systems can alert the user when saturation is adequate but the patient is requiring more $\mathrm{O}_{2}$ than before. Obviously, nothing will replace the proper assessment and interventions the experienced clinician can do at the bedside. We see closedloop $\mathrm{F}_{\mathrm{IO}_{2}}$ as a tool to assist in the repetitive task of increasing or decreasing oxygen.

Kevin Ward: What is the pathway through the FDA for this?

Claure: My involvement is primarily as an investigator. Our center is one of the centers participating in gathering the data to support the application to FDA. The process may be long, but seeking approval in the United States is necessary. ${ }^{4,5}$ In reference to the pathway, CareFusion, the device manufacturer, will be able to answer your question directly.

Owens: The neonatal data you showed reminds me of central sleep apnea in an adult. You are focused on $\mathrm{O}_{2}$ saturation, but the drops in $\mathrm{O}_{2}$ saturation are likely driven by changes in ventilation. Have you looked at incorporating end-tidal $\mathrm{CO}_{2}$ measurements? You mentioned using adaptive servo ventilation and trying to increase ventilation rather than just respond with more $\mathrm{O}_{2}$ during apneas. Is that something you've done? In the adults some people use dead space or bleed-in $\mathrm{CO}_{2}$ to keep ventilation stable. Have you looked at closed-loop ventilation versus closed-loop $\mathrm{O}_{2}$ ?

Claure: Yes, we have worked with volume-targeted ventilation, where the ventilator increases the pressure trying to maintain tidal volume within an adequate range. It is partly effective. It doesn't prevent the occurrence of the spells, but it does attenuate the resulting hypoxemia. We have tested 
targeted minute ventilation (also called mandatory minute ventilation), where the ventilator's mandatory rate increases in the event of hypoventilation, and it is also effective. We also developed and tested a system that increases both the rate and the pressure to maintain both tidal volume and minute volume, and this combined mode is quite effective, but it is still experimental.

Perhaps in the future there will be 2 systems running in parallel: one for closed-loop ventilation and the other for closed-loop oxygen saturation. When an infant is not intubated, things become more challenging, because there is less certainty of the efficacy of a backup ventilator mode. Fortunately, non-intubated infants usually have fewer and less severe fluctuations.

Treggiari: I have a comment regarding ventilation in adults. I appreciate the value of closed-loop in downtitration of $\mathrm{F}_{\mathrm{IO}_{2}}$, but not necessarily for up-titration. Indeed, closed-loop could expedite weaning the $\mathrm{F}_{\mathrm{IO}_{2}}$, as sometimes the patient has improved arterial blood gases but it takes several hours before ventilator changes are made. Based on my experience, I think an automatic mechanism would help expedite down-titration, but I would be more concerned with uptitration because, as you mentioned, we need to evaluate the cause of the desaturation. I think it's probably good to differentiate the processes of $\mathrm{F}_{\mathrm{IO}_{2}}$ weaning and $\mathrm{F}_{\mathrm{IO}_{2}}$ up-titration.

Claure: I agree. Closed-loop systems are quite effective in weaning. There is more control over oxygenation when $\mathrm{F}_{\mathrm{IO}_{2}}$ is being decreased. In contrast, when $\mathrm{F}_{\mathrm{IO}_{2}}$ is being increased, there is less control because the problem is usually related to ventilation. Our concern is that during routine care we often see $\mathrm{F}_{\mathrm{IO}_{2}}$ increased in what was supposed to be a transient response but actually becomes a prolonged $\mathrm{F}_{\mathrm{IO}_{2}}$ increase. The concern is rebound hy- peroxemia, which may have serious consequences in premature infants.

Kallet: In response to that comment and to Neil's [MacIntyre] comments, what might take care of that is a highbaseline alarm. So if you're performing routine care that results in transient desaturation requiring a few minutes to recover, then having a highbaseline alarm that's too vigilant will cause the whole idea to breakdown as a practical tool. If someone goes from $50 \% \mathrm{O}_{2}$ to a higher stable baseline of $70 \% \mathrm{O}_{2}$ for 20 minutes, then having a secondary alarm that tells you, "This is a real change in condition," would take care of that. The down side of that is more complexity in the alarms, requiring bedside clinicians to be more sophisticated in handling them. But I think they're on the right track in building up high and low baseline alarm levels. Having independent alarm delay times you could set would take care of a lot of those problems. But it definitely would make things more complicated.

McCoy: I think the future is autoadjusting for home care, which takes care of a lot of the problems in home $\mathrm{O}_{2}$ therapy. One of the biggest problems is that patients are told, "Don't touch the dial, because you'll kill yourself," and if the device allows them to oxygenate without the fear of them turning the $\mathrm{O}_{2}$ up or down, it would be fantastic. I'm hoping the technology will evolve.

Recent articles ${ }^{6,7}$ on auto-adjusting home application said that the future is in that direction. The comment in the one from Italy was that it overcompensated. One of the things respiratory therapists do in the home is go one setting at a time, and one device went 3 settings in one go and overshot. I've tried to chase patients before where they're desaturating, but I can't catch up because they keep on desaturating, and a slow increase doesn't catch them. So this device is smart enough to start high and then comes back down, which I think is a good approach. I'm looking forward to these devices being commercialized.

Branson: Neil, I'll answer a couple of your comments. One is that Hamilton has Intellivent, which is ASV [adaptive support ventilation] with a combined $\mathrm{F}_{\mathrm{IO}_{2}} /$ PEEP controller. ${ }^{8}$ It uses the high- $\mathrm{F}_{\mathrm{IO}_{2}} / \mathrm{PEEP}$ algorithm from the ARDS Network ARMA trial ${ }^{9}$ and then the high-PEEP/ $\mathrm{F}_{\mathrm{IO}_{2}}$ table from the ALVEOLI trial, ${ }^{10}$ so the $\mathrm{F}_{\mathrm{IO}_{2}}$ goes up first, fastest, and then, once that's adjusted, the PEEP starts to be titrated, and then it gets reduced in the opposite direction. It has only very preliminary evidence, from Europe, not the United States.

When we built our system, we were funded by the military, so there are different goals. First, who's caring for the patient? The military medic is like an EMT [emergency medical technician], so understanding how to use a ventilator is kind of beyond their scope. And in the military there's often no access to the patient in the back of the helicopter or other vehicle. Our system is meant to conserve $\mathrm{O}_{2}$ by giving the lowest possible $\mathrm{F}_{\mathrm{IO}_{2}}$, and because head injury is the signature injury of the present war, to prevent hypoxemia and secondary brain injury. If $\mathrm{S}_{\mathrm{pO}_{2}}$ goes below $88 \%$, it increases the $\mathrm{F}_{\mathrm{IO}_{2}}$ rapidly to $100 \%$, and then returns it slowly.

I'm not sure that system would be helpful in a regular ICU, but I have been impressed by the papers by the Dutch group ${ }^{11}$ and others, ${ }^{12}$ and a paper in Respiratory Care from the Mayo Clinic demonstrating time after time, especially surgical and neurosurgical patients being on $\mathrm{F}_{\mathrm{IO}_{2}}$ of 40 to $50 \%$ with $\mathrm{P}_{\mathrm{aO}_{2}}$ of $150 \mathrm{~mm} \mathrm{Hg}$ and absolutely no intervention, not only for hours but for days. ${ }^{13}$ And that might need to be addressed.

Nelson, what about all this stuff that's come out recently about the target? There's the paper in which ${ }^{14}$ a lower target was associated with worse 
outcomes at 36 weeks, and that more hypoxemic events are associated with an increase in ROP [retinopathy of prematurity]. Is it going to be that the machine comes out with a target, or do you think it's important for the clinician to set the target for each individual patient?

Claure: I think the clinician has to be the one responsible for setting the target. For many years avoidance of hyperoxemia was the goal and oxygen saturation targets were being lowered. Saturation targets under $92 \%$ or $90 \%$ were being used with the goal of staying away from very high saturation. Randomized trials were conducted testing the hypothesis that targeting below 90\% would decrease retinopathy and improve respiratory outcome. In one of these trials, respiratory outcome was improved and the incidence of retinopathy was reduced, but mortality increased. ${ }^{14,15}$ These findings opened a new set of questions. There are lots of new developments, and everybody is awaiting the results of other large trials, which will report data from over 4,000 cases. ${ }^{16}$ At this point nobody can really recommend what is the optimal target saturation range for preterm infants. I do think avoiding the 2 extremes ranges of oxygen saturation is necessary.

In regards to the fluctuations in saturation, there may be more than subtle effects to these relatively low saturations, especially if the exposure is prolonged. It should be noted that the actual effects of the target range are not necessarily attributable to the closed-loop systems. A closed-loop $\mathrm{F}_{\mathrm{IO}_{2}}$ system will target the range set by the clinician, and if the range is not adequate, the results are not necessarily due to the closed-loop system.

1. Lellouche F, Bouchard PA, Laubscher T, Blackburn S, L'Her E, Wysocki M. Prospective randomized controlled study comparing conventional ventilation versus a fully closed-loop ventilation (IntelliVent) in post cardiac surgery ICU patients. Intensive Care Med 2010,36(Suppl):S752.

2. Arnal JM, Wysocki M, Novotni D, Demory D, Lopez R, Donati S, et al. Safety and efficacy of a fully closed-loop control ventilation (IntelliVent-ASV) in sedated ICU patients with acute respiratory failure: a prospective randomized crossover study. Intensive Care Med 2012;38(5):781-787.

3. Herber-Jonat S, Rieger-Fackeldey E, Hummler H, Schulze A. Adaptive mechanical backup ventilation for preterm infants on respiratory assist modes: a pilot study. Intensive Care Med 2006;32(2):302-308.

4. United States Food and Drug Administration. Medical devices: 510(k) clearances. http:// www.fda.gov/MedicalDevices/Productsand MedicalProcedures/DeviceApprovalsand Clearances/510kClearances/default.htm. Last updated June 2009. Accessed May 14, 2012.

5. United States Food and Drug Administration. Medical devices: PMA approvals. http:// www.fda.gov/MedicalDevices/Productsand MedicalProcedures/DeviceApprovalsand Clearances/PMAApprovals/default.htm Last updated June 2009. Accessed May 14, 2012.

6. Rice KL, Schmidt MF Buan JS, Lebahn F, Schwarzrock TK. AccuO ${ }_{2}$ oximetry driven oxygen conserving device versus fixed dose oxygen devices in stable COPD patients. Respir Care 2011;56(12):1901-1905.

7. Cirio S, Nava S. Pilot study of a new device to titrate oxygen flow in hypoxic patients on long-term oxygen therapy. Respir Care 2011;56(4):429-434.

8. Arnal JM, Wysocki M, Novotni D, Demory D, Lopez R, Donati S, Granier I, Corno G, Durand-Gasselin J. Safety and efficacy of a fully closed-loop control ventilation (IntelliVent-ASV) in sedated ICU patients with acute respiratory failure: a prospective randomized crossover study. Intensive Care Med 2012;38(5):781-787.

9. NHLBI Acute Respiratory Distress Syndrome Network. Ventilation with lower tidal volumes as compared with traditional tidal volumes for acute respiratory distress syndrome. N Engl J Med 2000;342(18): 1301-1308.

10. Brower RG, Lanken PN, MacIntyre N, Matthay MA, Morris A, Ancukiewicz M, et al; National Heart, Lung, and Blood Institute ARDS Clinical Trials Network. Higher vs lower positive end-expiration pressures in patients with the acute respiratory distress syndrome. $\mathrm{N}$ Engl $\mathrm{J}$ Med 2004;351(4):327-336.

11. de Jonge E, Peelen L, Keijzers PJ, Joore H, de Lange D, van der Voort PH, Bosman RJ, de Waal RA, Wesselink R, de Keizer NF. Association between administered oxygen, arterial partial oxygen pressure and mortality in mechanically ventilated ICU patients. Crit Care 2008;12(6):R156.

12. Kilgannon JH, Jones AE, Parrillo JE, Dellinger RP, Milcarek B, Hunter K, Shapiro NI, Trzeciak S; Emergency Medicine Shock Research Network (EMShockNet) Investigators. Relationship between supranormal oxygen tension and outcome after resuscitation from cardiac arrest. Circulation 2011; 123(23):2717-2722.

13. Rachmale S, Li G, Wilson G, Malinchoc M, Gajic O. Practice of excessive $\mathrm{F}_{\mathrm{IO}_{2}}$ and effect on pulmonary outcomes in mechanically ventilated patients with acute lung injury. Respir Care 2012;57(11):18871893.

14. SUPPORT Study Group of the Eunice Kennedy Shriver NICHD Neonatal Research Network, Carlo WA, Finer NN, Walsh MC, et al. Target ranges of oxygen saturation in extremely preterm infants. N Engl J Med 2010;362(21):1959-1969.

15. Stenson B, Brocklehurst P, Tarnow-Mordi W; U.K. BOOST II trial; Australian BOOST II trial; New Zealand BOOST II trial. Increased 36-week survival with high oxygen saturation target in extremely preterm infants. N Engl J Med 2011;364(17): 1680-1682.

16. Askie LM, Brocklehurst P, Darlow BA, Finer N, Schmidt B, Tarnow-Mordi W; NeOProM Collaborative Group. NeOProM: Neonatal Oxygenation Prospective Meta-analysis Collaboration study protocol. BMC Pediatr 2011;11:6. 